Article

\title{
Our Daily Communicative Contexts: More Evidence for the Food Environment Puzzle
}

\author{
Eulàlia P. Abril * and Carrie O'Connell
}

Department of Communication, The University of Illinois, Chicago, IL 60607, USA; coconn9@uic.edu

* Correspondence: eulalia@uic.edu

\begin{abstract}
Much of the research on food environments suggests that problematic access to healthy food restricts its consumption, contributing to adverse outcomes such as obesity, stroke, and heart disease. In addition to these direct relationships, we propose indirect relationships involving the Communication Mediation Model (CMM). Using nationally representative survey data from 1435 adults in the United States, we explore the multipronged role that perceived food environments play in shaping communication, attitudes, and reflective food consumption, considering communicative contexts. Results indicate a negative correlation between the perception of a difficult food environment and reflective consumption, supporting prior research. Most importantly, the food environment is also negatively correlated with news media use, discussion, and attitudes about healthy eating within the CMM. Our findings suggest that indirect communication effects of the food environment on reflective consumption compound the detrimental role of its direct effects.
\end{abstract}

Keywords: communicative contexts; perceived food environment; reflective food consumption; communication mediation model

Citation: Abril, Eulàlia P., and Carrie

O'Connell. 2021. Our Daily

Communicative Contexts: More

Evidence for the Food Environment Puzzle. Journalism and Media 2: 499-514. https://doi.org/10.3390/ journalmedia2030030

Academic Editor:

Andreu Casero-Ripollés

Received: 25 June 2021

Accepted: 18 August 2021

Published: 27 August 2021

Publisher's Note: MDPI stays neutral with regard to jurisdictional claims in published maps and institutional affiliations.

\section{Introduction}

Low intake of healthy foods (e.g., fresh fruits and vegetables, whole grains) is among the leading factors in obesity (National Institutes of Health, National Heart, Lung, and Blood Institute 2017), heart disease, stroke, and type-2 diabetes (Micha et al. 2017). Additionally, $45 \%$ of all cardiometabolic deaths (due to heart disease, stroke, and type 2 diabetes alone) were associated with suboptimal intake of foods; namely too many unhealthy and too few healthy foods (Jardim et al. 2019).

For many Americans, poor access to healthy foods is a major barrier to healthy food habits. Studies looking at disparities in geographic access to healthy foods show a correlation between localized access and positive health outcomes (Larson et al. 2009; Walker et al. 2010; Wang et al. 2019). However, the literature on food environments far from confirms a significant and negative relationship between lacking food environments and healthy eating (Black et al. 2014; Caspi et al. 2012; Pitt et al. 2017). Part of the problem is the heterogeneity in defining and measuring food environments, which can be analyzed from community nutrition (e.g., neighborhood stores), organizational nutrition (e.g., what schools offer), consumer nutrition (e.g., what stores contain), and perceived nutrition (self-reported) perspectives (see Glanz et al. 2005). Compounding these conceptual and methodological issues, Caspi and colleagues also found differences according to how those food environments were dimensioned in terms of availability, accessibility, affordability, acceptability, and accommodation (Caspi et al. 2012).

In addition to these conceptual and measurement issues, one overlooked factor already outlined by Glanz et al. (2005) that has received relatively little traction is the communication and media environment. Evidence suggests that certain media (social media, gaming) were negatively associated with fruit and vegetable consumption (Albert 2017). However, media comprises more than entertainment media. For instance, the news media environment and the subsequent discussion it produces, as delineated in the Communication 
Mediation Model (McLeod et al. 1996), have explanatory power as to how news media use can lead to desirable outcomes (e.g., voting and civic participation; Cho et al. 2009; Shah et al. 2005), including healthy eating habits (Kwon et al. 2013).

Looking at Glanz and colleagues' model (Glanz et al. 2005), the proximal psychosocial constructs (demographics, psychosocial factors, perceived environment) are especially wellpositioned to include the news media environment and posterior interpersonal discussion. Additionally, one common denominator among studies of the food environment is that they mostly focus on the direct relationship between tangible external factors like geographic, time, or financial constraints and health outcomes, thus overlooking the potential complex relationships among individual-level variables and the food environment. By excluding the impact of food environments on news media use, everyday talk, or attitudes, these studies potentially underestimate the adverse effects that food environments lacking in healthy food options may have on healthy food consumption.

In sum, understanding the food environment is complex, yet most models have relied solely on direct effects. Our study examines the relationships between various elements of our daily communicative contexts and reflective food consumption (consumption considerations such as "buy organic" or "buy local" that correlate highly with healthy food consumption; Torjusen et al. 2001) using the Communication Mediation Model (CMM; McLeod et al. 1996) on nationally-representative survey data from the United States. Communication contexts are conceptualized as factors of influence on everyday living outcomes from a communication perspective, which ultimately shape perception formation. Our results contribute to the understanding of communicative contexts for the case of reflective food consumption, which has potential for application to many other healthy living outcomes (Arena et al. 2017). Given the obesity epidemic and its upward trend in the last generation (Ogden et al. 2015), coupled with the salience of cardiometabolic disease in U.S. mortality rates (U.S. Department of Health and Human Services, Centers for Disease Control and Prevention, and National Center for Health Statistics 2016), further attention must be given to understanding the influence of food environments in order to reverse these trends and understand the complex relationships between food environments and healthy food consumption.

In the following sections, we explain prior applications of the Communication Mediation Model (CMM) and detail how our hypotheses fit into the CMM (see Figure 1). We explicate the role of communication contexts, perceived food environments, reflective food consumption, and CMM constructs related to healthy food consumption. Additional sections include an explication of methods and measures, discussion, and conclusion.

\section{Related Literature and the Communication Mediation Model}

The CMM is a model of human communication that suggests that interpersonal and mass communication are dependent and complementary forms of discourse (McLeod et al. 1996; Shah et al. 2005). With messages emanating from mass media, ensuing conversations between members of a community, group, or dyad play a mediating role between the initial consumption of the message and subsequent attitudes and behaviors prompted by that messaging (Cho et al. 2009; Friedland and McLeod 1999; McLeod et al. 1996). Originally, the CMM involved an O-S-O-R model (Markus and Zajonc 1985). The first O (orientations) entails individual attributes, core values, and community or context; the $S$ (stimulus) entails communication such as media use or interpersonal discussion; the second $\mathrm{O}$ represents subsequent orientations (attitudes, knowledge, cognitive complexity, or political efficacy) that can mediate the relationship between communication and participation; and the $\mathrm{R}$ represents the subsequent behavioral response (Markus and Zajonc 1985), such as food consumption. 


\subsection{Communicative Contexts}

Communicative contexts as factors of influence include the mass media environment (where the news media environment belongs), the interpersonal networks of discussion, the social media environment, the technology environment, and the physical environment within which the food environment belongs. This study focuses on the food environment together with the communicative contexts considered in the CMM, specifically the news media environment, the interpersonal networks of discussion, and the social media environment.

Communicative contexts represent a novel approach to understanding healthy food consumption by considering typical communication variables vis-a-vis food environments. Our contribution considers the relationship between the perceived food environment and reflective food consumption - as is tradition in the literature, in a direct way (Alber et al. 2018; Caspi et al. 2012; Chen et al. 2016; Flint et al. 2013)—but also introduces the CMM, thus crafting a cohesive narrative that emphasizes what is common and habitual-and basically acceptable-about the foods we choose to consume.

\subsection{The Perceived Food Environment}

One of the most significant factors in cultivating healthy food consumption habits is access to healthy food. Traditionally, what defines a healthy food environment, and conversely a food desert, has been the ubiquity and proximity of retail food stores (Black et al. 2014; Caspi et al. 2012; Lucan et al. 2014; Morland and Evenson 2009). Studies that identify food environments in this manner-as availability and access to supermarkets and smaller grocery stores-show a positive correlation between lack of access and increased BMI and obesity (Courtemanche and Carden 2011; Dubowitz et al. 2012; Powell et al. 2007, Wang et al. 2019). Others (Glanz et al. 2005) have conceptualized food environments as fitting into three categories: (a) community nutrition environment (e.g., types of stores), (b) the consumer nutrition environment (e.g., availability of options within a store), and (c) the organizational nutritional environment (e.g., home, work, school). On a macro scale, these environments are influenced by media and advertising, which intersect with micro influences such as individual, psychosocial, and sociodemographic factors (Pitt et al. 2017).

Beyond these particular conceptualizations of dimensional food environments, evidence on the relationship between food environments and healthy outcomes is mixed at best. For instance, the availability of fruits and vegetables in rural versus urban areas yields mixed results as a factor for obesity when gender is considered (Wang et al. 2019). Recent studies on the connection between obesity and food swamps, or densely populated establishments that offer high-calorie fast food and junk food, illustrate a significant positive correlation (Cooksey-Stowers et al. 2017). When looking at affordability, evidence shows that when fruits and vegetables (essential for a healthy diet; https:/ / www.choosemyplate.gov; accessed 1 February 2021) are too expensive in deprived neighborhoods, consumption of these foods is often reduced. In other cases, the presence of a new fully fledged grocery store brings about little change (Dubowitz et al. 2015). One suggested avenue to resolve the inconsistent results may be to use a mediation model in which psychosocial variables mediate the relationship between a lacking food environment and healthy eating outcomes (Thompson et al. 2013).

Additionally, and to look at the role of food environments from a national perspective to obtain generalizable data, the perceived food environment may be an ideal construct since it is determined at the individual level and allows for the inclusion of participants from any location in the nation. Traditionally, in areas with supermarkets, residents perceive that they have access to healthier foods, whereas those in areas with smaller markets perceive their healthy options to be limited (Moore et al. 2008). When residents perceive that the quality of food in their area is high, they are more likely to consume fruits and vegetables (Alber et al. 2018). This echoes the findings of Lucan and Mitra (2012), who suggest that more negatively perceived (e.g., difficult or scarce) food environments correlate with less 
healthy eating. Therefore, understanding these perceptions outside of traditional concepts of "food desert" or "food swamp" is warranted.

\subsection{Reflective Food Consumption}

Reflective food consumption (Torjusen et al. 2001) refers to food consumption considerations involving evaluation and thought from the individual. Reflective food consumption encompasses consideration upon various levels of the food system: from how food is produced and the environmental and ethical concerns relating to that production, to consumption itself (Torjusen et al. 2001). Reflection about consumption relates to healthy eating (Mai and Hoffmann 2015), but it is not the only factor in reflective food consumption. For instance, fresh fruits and vegetables are considered healthy, but their consumption alone does not necessarily indicate reflective consumption on the part of the consumer. To be reflective food consumption, further evidence of concern for the broader food system is necessary. Examples of foods that indicate a broader concern for the food system include organic, non-GMO, and local foods. Similarly, consumer behaviors that illustrate active cognitive appraisal, such as reading and considering labels when shopping, are factors that highly correlate with healthy food consumption (Torjusen et al. 2001). Given the importance of the perceived food environment (conceptualized as deficient in healthy foods) on healthy food consumption, we propose that the perception of a difficult food environment will be negatively correlated to reflective food consumption (H1).

\subsection{Beyond Direct Effects of the Perceived Food Environment}

Consumers are constantly bombarded with advertisements on television, the internet, and outdoor marketing (billboards, banners, etc.) about food and beverages-most of which focus on unhealthy items (Kornfield et al. 2015). Similarly, news about food influences our perception of what is healthy and unhealthy (Sundin et al. 2016). Discussion within our interpersonal networks then helps us make sense of what we learn in the media, thereby functioning as an additional vehicle of information. In this regard, what is perceived as worthy of discussion in an interpersonal or social media context may also communicate what is valued, common, or habitual. For instance, if one's food environment is scarce, there may be little incentive to talk about the importance of healthy eating or to read the news about the health effects of what people consume. To examine the hypothesis that there may be indirect effects of the food environment, we draw on the CMM.

In the context of the food environment, motivations to seek and consume health news could be influenced by corresponding environments (Cho et al. 2009; Kaase and Kohut 1996; Shah et al. 2005). We propose that when there is an unhealthy food environment, it could hinder news media seeking and exposure, as well as the ability to think that it matters to learn about food and nutrition. For instance, a food environment lacking in fresh fruits or vegetables, organic foods, or local foods usually translates into less appetite for health and food-related news media use than when individuals are exposed to a healthier food environment. Therefore, we propose that the perception of a difficult food environment will be negatively correlated with the use of news about the health effects of food (H2).

Multiple studies note that exposure to health messaging leads to information-seeking and interpersonal communication, which in turn leads to positive health behaviors (McKinley 2008; Ramírez et al. 2013; Rimal et al. 1999). The extent to which individuals seek and process health information is determined by their level of involvement with the topic (Rimal et al. 1999). If individuals perceive that a health topic will have a significant impact on their lives, they are more likely to invest in and engage with related messaging and subsequent behavior. 
Within CMM, talk is a mediating variable, leading to either subsequent orientations or health outcomes and influenced by news media use (Kwon et al. 2013). Talk can also be influenced by the environment. For example, an interest in healthy food could be triggered by a healthy food environment or halted by a lack thereof. Some of the content about food and nutrition talk involves preparation times for meals, choices of ethnic food, and knowledge of healthy food choices (Kilanowski 2010), which can be triggered by a healthy food environment. A difficult food environment is lacking in raw foods, and so talkrelated meal preparation and healthy choices may be much less prevalent. In discussion on public platforms centered on high caloric intake or alcohol, Nguyen et al. (2017) noted higher mortality rates and incidents of binge drinking in the corresponding geographic area. With this in mind, we propose that the perception of a difficult food environment will be negatively correlated with food talk (H3) in the form of face-to-face or mediated communication.

One of the CMM developments included an evaluative attitude and considered CMM in the context of healthy food consumption (Kwon et al. 2013). In our model, we take the approach of Jung et al. (2011) and consider attitudes as the outcome of reasoning that takes place in everyday talk. Conventional definitions of attitude include attitudes as psychological tendencies expressed by evaluating a given entity with different levels of favor or disfavor (Eagly and Chaiken 1993). This definition implies more than one dimension of attitude.

Though talk and other orientations usually influence attitudes in the CMM, it is plausible that the food environment is also related to the provenance of these attitudes. For instance, it is possible that in addition to quality, cost, and access, factors such as time and familiarity with food environments may shape perceptions that directly contribute to the formation of attitudes and behaviors. To our knowledge, the literature has yet to explore the relationship between the perceived food environment and attitudes. With this in mind, we propose that the perception of a difficult food environment will be negatively correlated with an evaluative (H4a) and tendency attitude (H4b).

Overall, we are interested in assessing whether the communication contexts help explain the perceived food environment, so we will assess this contribution at the end (RQ1). Figure 1 below addresses our aims as well as highlights what our contributions entail.

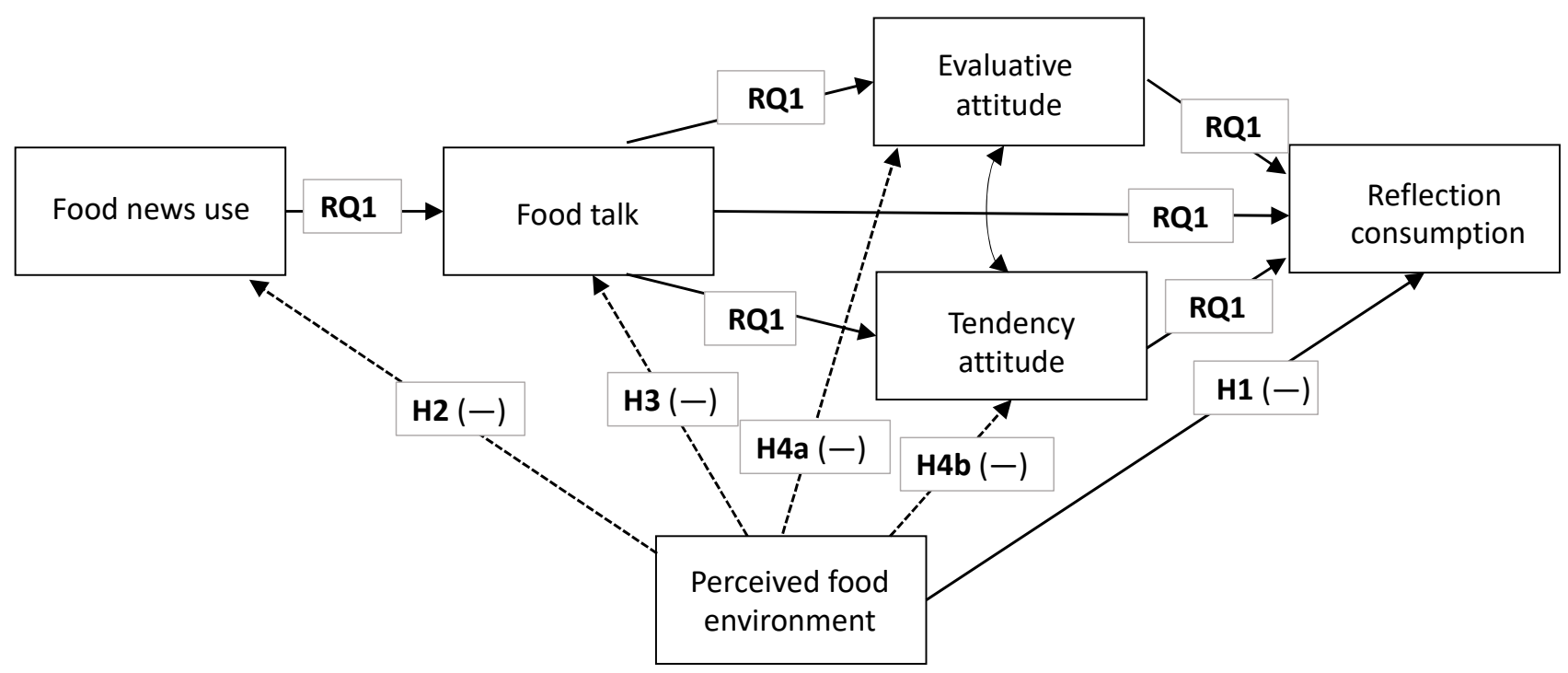

Figure 1. Hypotheses and research questions proposed. Note: The RQ1 corresponds to the CMM testing. Dotted lines represent this paper's main contributions. 


\section{Methods}

\subsection{Data}

Data in this study were secondary and obtained from the 2016 ATP (American Trends Panel; Wave 17 (see supplementary file)) by the Pew Research Center (collected between 10 May and 6 June). The 2016 APT had an approved ethics protocol (Internal Review Board approved). The final sample $(N=4563)$ consisted of a national representative online panel of adults 18 years or older in the United States living in households. Consenting adults participated in the panel via self-administered web surveys $\left(N_{w}=4091\right)$ and snail mail $\left(N_{m}=472\right)$. Fielding was conducted by Abt SRBI. The survey was administered in English and Spanish. The margin of sampling error for full sample weighted estimates was $\pm 2.31 \%$ (Abt SRBI 2016).

The contacted sample consisted of 5670 members of the ATP, a probability-based online panel of adults in the United States. The ATP originally consisted of 8314 panelists, but 371 of them requested to be removed prior to the start of Wave 17; an additional 2273 panelists were also removed because they had not responded to any of the panel surveys since their recruitment or had since been unable to be reached by email, phone, or mail. Sampling featured a simultaneous mixed-mode design. Panelists who used the internet and provided an email address participated via a self-administered web survey; otherwise, adults participated via a mail survey. Using AAPOR's (American Association for Public Opinion Research) standards, the response rate for the sample was RR1 $=81 \%$ for the web panelists and RR1 $=76.5 \%$ for the mail panelists ${ }^{1}$ (for further details, see Abt SRBI 2016).

Data were provided with survey weights necessary to support reliable inference to the target population of adults in the United States. The Pew Research Center computed the full sample weight in three main stages: (a) base weight adjusting for differential probabilities of selection; (b) propensity adjustment for attrition; and (c) calibration to demographic distributions for the target population (Abt SRBI 2016). Thus, the use of weights makes our sample generalizable.

Wave 17 covered three topics (health and medicine, food and health, and the environment and green consumption), each of which had its own sample. In this study, only questions related to food and health were retained, thus effectively making this study's sample $N=1435$.

\section{Measures}

Outcome variable. Self-reported reflective food consumption (reflective consumption) was measured averaging four items that inquired about household consumption in the past 30 days, on the following scale: $1=$ never, 2 = about once, $3=$ several times. The items were "buy organic foods (including fruits, vegetables, meat, fish, grains and packaged foods)", "buy fruits and vegetables grown in your local area", "buy GMO-free food, which is food labeled as having no genetically modified ingredients", and "decide whether to buy a food product because of what you read in the nutrition and ingredients label" $(M=2.22$, $S D=0.59$; Cronbach's $\alpha=0.70)$. Exploratory factor analysis with Promax rotation yielded a one-factor model that had a good fit $\left(\chi^{2}=0.42, n\right.$. s.). We recognize that our variable reflective food consumption is an imperfect proxy for healthy food consumption (which would have been a more valid outcome variable had it been available). ${ }^{2}$

The food environment. The perceived food environment was measured with a single item that inquired about the difficulty of finding organic foods in one's community on a scale from $1=$ very easy to find to $4=$ very hard to find $(M=1.87, S D=0.76)$. While organic foods are only a fraction of what is considered healthy foods (see discussion above about the dependent variable, reflective consumption), Inglis and colleagues (Inglis et al. 2008) found that quality of healthy foods (e.g., organics) was more important than the availability of fruits and vegetables. Moreover, in our sample, only $25 \%$ had not purchased organic foods in the last 30 days, but this does not translate necessarily into not knowing about its prevalence in the environment. It should also be noted that organic foods go beyond fruits and vegetables and also include meat and grains. So, in line with what we concluded 
above, estimating the food environment based on organic foods may underestimate the true relationship of a difficult food environment, making it a conservative measure of true difficult environments.

Although the food environment is a single-item measure, it taps into several dimensions of the perceived food environment that have been shown to be correlated with healthy food consumption: "community," which includes the neighborhood but also the work environment (Cummins 2007), and "difficulty," which encompasses distance but also cost. Single-item measures have been used in prior studies (Caldwell et al. 2009; Gase et al. 2016).

Communication variables. News use about the health effects of food (food news use) was computed averaging two items: (a) news media use about the health effects of what people eat and drink on a scale from $1=$ less often than a few times a month to $4=$ every day, and (b) use of conflicting news (consuming news with opposing views to other news) about the health effects of what people eat and drink on a scale from $1=$ not at all to $4=$ all the time $(M=2.85, S D=0.73 ; r=0.49)$. Food and nutrition news is usually presented as conflicting findings (see Nagler and Hornik 2012), and thus this variable was built taking into consideration the contradictory nature of news about food and nutrition. Food and nutrition talk (food talk) was quantified by asking participants about whether they had talked about food and nutrition with anyone in person, on the phone, or by email, text message, or social media in the past seven days (yes $=46 \%$ ). Whether talk happens (i.e., measuring talk as a categorical variable like in Geller et al. 2003) is a special case of measuring the frequency of talk, which is the gold standard to capture everyday talk used by the American National Election Studies and Pew Internet Research.

Attitudes. The evaluative attitude was gauged with one item that asked about the importance of healthy eating habits when it comes to improving an individual's chances of a long and healthy life, on a scale from $1=$ not at all important to $4=$ very important $(M=$ $3.68, S D=0.58$ ). The tendency attitude was assessed with one question about how well "my focus is on eating healthy and nutritious" described one's overall approach to eating, on a scale from $1=$ not at all to $4=$ very well $(M=2.89, S D=0.72)$.

Control variables. Several demographic variables were gathered, including gender ( $52 \%$ female); age ( $\mathrm{Mdn}=30-49$ years old); education ( $\mathrm{Mdn}=$ some college); income (Mdn $=\$ 40,000-\$ 50,000)$; whether participants lived with a partner (54\% did) to monitor for increased healthiness when individuals live together (Kemmer et al. 1998); measures for ethnicity and race-Black (11\%), Hispanic (14\%), and Asian (3\%); and the extent to which participants were vegetarian or vegan with $1=$ neither vegetarian or vegan, $2=$ mostly vegetarian or vegan, $3=$ strict vegetarian or vegan $(M=1.12, S D=0.41)$ to control for a potential disposition toward healthy foods (Sun 2008). A summary of all these statistics is presented in Table 1.

Table 1. Descriptive Statistics.

\begin{tabular}{ccc}
\hline Variable & Mean/Percentage/Median & SD \\
\hline Reflective consumption & 2.22 & 0.59 \\
Food environment & 1.87 & 0.76 \\
Evaluative attitude & 3.68 & 0.58 \\
Tendency attitude & 2.89 & 0.72 \\
Food talk (yes) & $46 \%$ & \\
Food news & 2.85 & 0.73 \\
Gender (female) & $52 \%$ & \\
Age & $30-49$ years old & \\
Income & $\$ 40,000-\$ 50,000$ & \\
Partner (yes) & $54 \%$ & \\
Black & $11 \%$ & \\
\hline
\end{tabular}


Table 1. Cont.

\begin{tabular}{ccc}
\hline Variable & Mean/Percentage/Median & SD \\
\hline Education & Some college & \\
Latinx & $14 \%$ & \\
Asian & $3 \%$ & 0.41 \\
\hline Vegetarian & 1.12 &
\end{tabular}

\subsection{Analysis}

To assess H1-H4 and RQ1, we ran a path analysis model based on the CMM and controlled for an array of demographic variables and dispositions (for each variable in the model) using MPlus. Assessment of the hypotheses will be based on the significance of the path analysis coefficients and total effects given adequate model fit. All the results reflect the use of survey weights to account for differential probabilities of selection into the panel as well as differential nonresponse to the panel recruitment survey, the panel invitation, and the panel survey itself.

\section{Results}

Full and partial correlations are shown Tables 2 and 3, respectively. When looking at the dependent variable, reflective food consumption, $87 \%$ of participants in the sample consumed at least one item pertaining to reflective food consumption (organic, local), and about half of these participants did so several times in the last 30 days (see Figure 2). The USDA (United States Department of Agriculture) does not provide an equivalent measure for comparison. However, the USDA reports that organic consumption has increased in the last few years - similar to the demand for non-GMO and local foods (see https: / / www.usda.gov / for more information; accessed 1 February 2021).

Table 2. Correlations among all variables.

\begin{tabular}{|c|c|c|c|c|c|c|c|c|c|c|c|c|c|c|}
\hline & $\begin{array}{l}\text { Food } \\
\text { Env. }\end{array}$ & $\begin{array}{l}\text { Eval. } \\
\text { Att. }\end{array}$ & $\begin{array}{l}\text { Tend. } \\
\text { Att. }\end{array}$ & $\begin{array}{c}\text { Food } \\
\text { Talk }\end{array}$ & $\begin{array}{l}\text { Food } \\
\text { News }\end{array}$ & Gen. & Age & Educ. & Inc. & Part. & Black & Latin & Asian & Veg. \\
\hline Refl. cons. & 0.23 & 0.18 & 0.34 & 0.23 & 0.17 & 0.03 & 0.05 & 0.15 & 0.10 & 0.08 & -0.07 & 0.04 & 0.02 & 0.15 \\
\hline Food env. & - & -0.18 & -0.07 & -0.11 & -0.15 & 0.03 & -0.13 & -0.16 & -0.10 & -0.04 & 0.06 & 0.03 & -0.02 & 0.02 \\
\hline Evaluative att. & & - & 0.28 & 0.14 & 0.13 & 0.04 & -0.03 & 0.06 & 0.02 & -0.00 & 0.02 & 0.12 & 0.03 & 0.00 \\
\hline Tendency att. & & & - & 0.16 & 0.19 & 0.10 & 0.11 & 0.05 & 0.01 & -0.03 & 0.04 & 0.03 & -0.03 & 0.17 \\
\hline Food talk & & & & - & 0.13 & 0.13 & -0.09 & 0.25 & 0.12 & -0.02 & -0.02 & -0.05 & -0.01 & 0.14 \\
\hline Food news & & & & & - & 0.08 & 0.14 & -0.00 & -0.02 & 0.00 & 0.08 & 0.03 & -0.02 & -0.01 \\
\hline Gender & & & & & & - & 0.02 & -0.01 & -0.10 & -0.05 & 0.01 & 0.01 & -0.06 & 0.02 \\
\hline Age & & & & & & & - & -0.04 & 0.07 & 0.03 & -0.02 & -0.17 & 0.12 & -0.11 \\
\hline Education & & & & & & & & - & 0.53 & 0.09 & -0.11 & -0.09 & 0.07 & 0.03 \\
\hline Income & & & & & & & & & - & 0.36 & -0.14 & -0.12 & 0.06 & -0.06 \\
\hline Partner & & & & & & & & & & - & 0.21 & -0.02 & -0.01 & -0.03 \\
\hline Black & & & & & & & & & & & - & 0.13 & 0.07 & 0.11 \\
\hline Latinx & & & & & & & & & & & & - & -0.06 & -0.01 \\
\hline Asian & & & & & & & & & & & & & - & 0.05 \\
\hline
\end{tabular}

Note: All correlations are zero-order Pearson correlations. The significant (two-tailed) correlations $(p \leq 0.05)$ are the non-shaded cells; $N=1435$.

Table 3. Partial Correlations among Model Variables.

\begin{tabular}{cccccc}
\hline & Food Env. & Evaluative Att. & Tendency Att. & Food Talk & Food News \\
\hline Refl. cons. & -0.20 & 0.18 & 0.32 & 0.19 & 0.17 \\
Food env. & - & -0.18 & -0.07 & -0.09 & -0.14 \\
Evaluative att. & & - & 0.27 & 0.13 & 0.12 \\
Tendency att. & & - & -13 & 0.16 \\
Food talk & & & & - & 14 \\
\hline
\end{tabular}

Note: All correlations controlled for age, gender, education, income, race (Black, Asian, and Latinx), cohabitating status, and vegetarian/vegan status. The significant (two-tailed) correlations $(p \leq 0.05)$ are the non-shaded cells; $N=1435$. 


\section{Reflection Food Consumption}

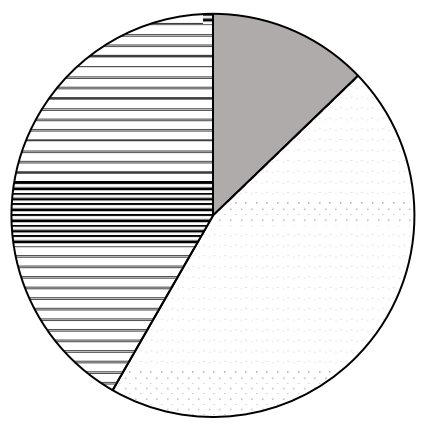

$\square$ Never $\square$ About once 目 Severaltimes

Figure 2. Frequency distribution of reflective consumption. $N=1435$.

Similarly, for the frequency distribution of the perceived food environment (see Figure 3), we observe that $82 \%$ of participants reported that it was easy or very easy to find organic foods in their community. It is challenging to contrast this statistic to existing national data, but, for comparison, the USDA reports that $80 \%$ of the U.S. population is within 5 miles of three supermarkets, while only $1.8 \%$ is without a vehicle and within more than one mile of a supermarket (Ver Ploeg et al. 2012), which provides validity to our finding.

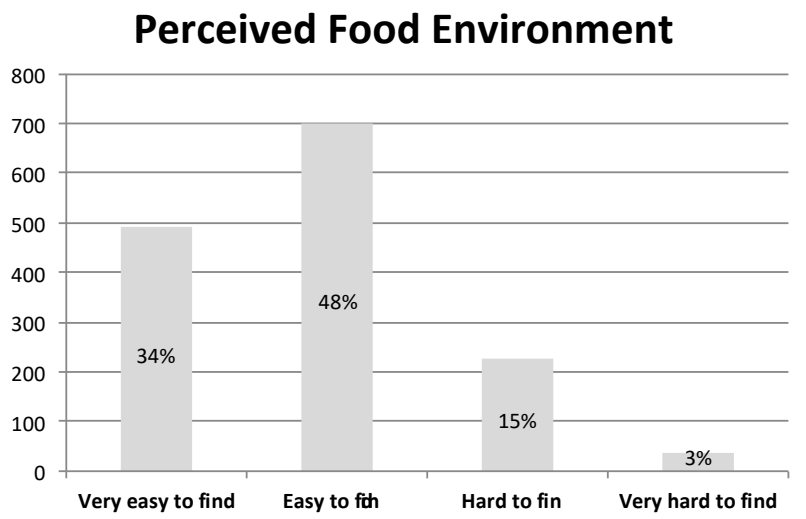

Figure 3. Frequency Distribution of the Perceived Food Environment. N=1435.

To test the hypotheses posed regarding the relationship between food news use, food talk, attitudes about healthy eating, and reflective food consumption (with the food environment as an exogenous factor) on a CMM model, we ran a path analysis model.

\subsection{Direct Relationship of a Difficult Food Environment with Reflective Food Consumption}

The path analysis model predicting reflective food consumption recall had a good fit to the data. The Likelihood Ratio test (LR) was significant but had a low chi-square value $\left(\chi^{2}=12.09, p=0.00\right)$. The Comparative Fit Index (CFI) (0.97) indicated a remarkable fit. Finally, the Root Mean Square Error of Approximation (RMSEA) also indicated a good fit (0.05), $90 \%$ CI [0.02, 0.07]. The model explained $20.2 \%$ of the variance.

Results $^{3}$ showed that the perception of a difficult food environment was negatively related to reflective food consumption $(\beta=-0.16, p=0.00)$. This supported H1. This statistic was also the total direct effect of the perceived food environment (See Figure 4). 


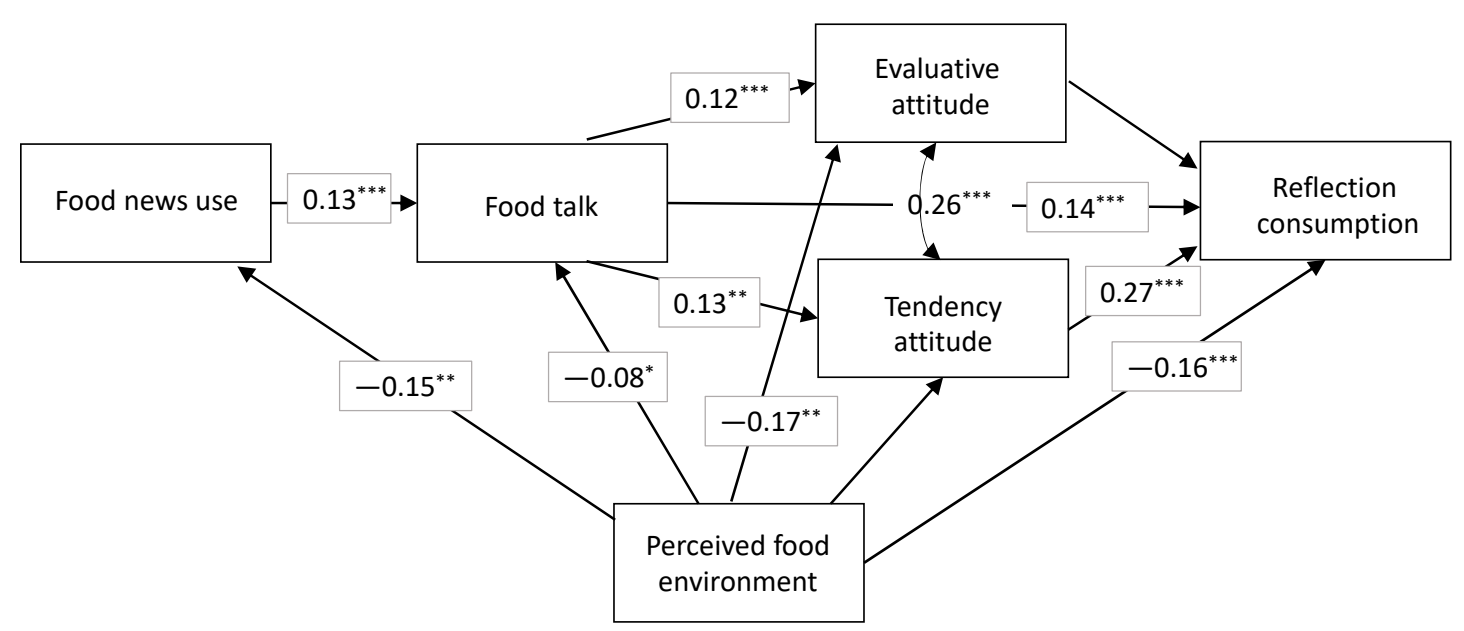

Figure 4. Path Analysis of the Food Environment Influence Using the CMM. Note: Statistics represent STDX standardized betas. ${ }^{*}$ corresponds to $p \leq 0.05 ;{ }^{* *}$ corresponds to $p \leq 0.01 ;{ }^{* * *}$ corresponds to $p \leq 0.001$. Dotted paths are non-significant. $N=1435$.

\subsection{Indirect Relationships of a Difficult Food Environment with Reflective Food Consumption}

The perception of a difficult food environment was negatively related to the use of news about the health effects of food ( $\beta=-0.15, p=0.00$ ), supporting H2. The perception of a difficult food environment was negatively related to food talk $(\beta=-0.08, p=0.04)$, which supported H3. Finally, the perception of a difficult food environment was negatively related to the evaluative attitude $(\beta=-0.17, p=0.00)$. This supported H4a. However, the perception of a difficult food environment was not negatively related to the tendency attitude $(\beta=-0.06, n . s$.$) , thus not supporting H4b. The total of the indirect effects of the$ perceived food environment on reflective consumption was small but significant $(\beta=-0.04$, $p=0.02)$, signaling the detrimental effect of the food environment beyond direct effects.

Given the support for H1-H4 (except for H4b), we can say that the food environment provides evidence that communication contexts in the form of a CMM model and in the framework of reflective food consumption matter (answering RQ1). In the following discussion section, we will evaluate these results and provide avenues for future research.

\section{Discussion and Conclusions}

Inadequate intake of healthy foods is a major factor underlying the high incidence of obesity, heart disease, stroke, and type-2 diabetes (Micha et al. 2017; National Institutes of Health, National Heart, Lung, and Blood Institute 2017). For years, studies have shown the causal relationship between difficult food environments (food deserts), the inadequate intake of healthy foods (Caspi et al. 2012; Lucan et al. 2014; Morland and Evenson 2009), and obesity or high BMI (Courtemanche and Carden 2011; Dubowitz et al. 2012; Powell et al. 2007) using different measures of the food environment, including perceived food environments (Alber et al. 2018; Caspi et al. 2012; Lucan and Mitra 2012). In this study, we fit the Communication Mediation Model (CMM) to data about reflective food consumption using the perceived food environment as an exogenous variable, which allowed for estimating the direct effect of food environments on reflective food consumption but also modeled communication pathways that indirectly affect reflective food consumption-akin to how external forces such as advertising infuse the CMM, leading to behavioral outcomes.

\subsection{Perceptions of a Difficult Food Environment}

Our results confirmed the negative relationship between a perceived lacking food environment and reflective food consumption (supporting H1), adding to the literature about the relationship between the food environment and food deserts (Alber et al. 2018; Caspi et al. 2012; Chen et al. 2016; Flint et al. 2013). We also showed a negative 
relationship between a problematic food environment and the use of and reflection about food news (supporting H2). Although this is a new result, it mimics the behavior of other environments such as the advertising environment, which Shah and colleagues showed had an effect on information seeking within the CMM (Shah et al. 2007), as well as social media environments (Gil de Zúñiga et al. 2017).

Results from our study also indicated a negative relationship between the lacking food environment and food talk (supporting H3). Similar to the relationship with attitudes, the food environment provides access to the information necessary to start or sustain a conversation about food and nutrition, which may be similar to the effects of the social or political environment on outspokenness by the spiral of silence (Abril and Rojas 2018; Noelle-Neumann 1974). For instance, a food environment with an abundance of organic foods makes the accessibility to organic foods more salient. In turn, this salience makes conversations about food and food-making more feasible than in an environment where organic foods are less available. However, we cannot test for the mechanism(s) by which this takes place given the existing data-something that future research might help address.

When conceptualizing the food environment as a communicative context- - that is, a factor of influence on healthy living outcomes from a communication perspective-it is easy to see (a) the work of other communicative contexts at play (e.g., the mass media, interpersonal networks), as well as (b) the possibility that these different communicative contexts can be related. For instance, an environment lacking in healthy foods may influence perceptions if those within an interpersonal network have limited or no exposure to healthy foods beyond that environment. In this regard, our findings showed a negative relationship between a problematic food environment and the evaluative attitude (supporting H4a) - the attitude about the importance of healthy eating habits in improving an individual's chances of a long and healthy life. This supports previous research by Kwon et al. (2013), which noted a relationship between (evaluative) attitudes and healthy food consumption.

Our findings also indicated that the evaluative attitude was related to the tendency attitude - the attitude about one's predisposition regarding healthy and nutritious intakewhich, in turn, was related to reflective food consumption (but H4b was not supported). With more reliable measures of both the evaluative and tendency attitudes, clarification of this potentially interdependent relationship may be possible, which is something future research should investigate. Attitudes have long been studied in the context of antecedents to behavior (Ajzen and Fishbein 1977), so food environments resulting in a relationship with attitudes is remarkable. We argue that the food environment works as a communicative context, providing a context in which some attitudes are formed while others are not. However, we do not have the data to explore the full mechanism of this relationship, so it could be that the food environment affects attitude accessibility (Roskos-Ewoldsen et al. 2004) or that it contributes to its formation-just as the objects in the environment contribute to the formation of attitudes (Eagly and Chaiken 1993; Fishbein and Ajzen 1975). This is an aspect, however, that only subsequent studies can help determine since we do not have measures to test it here.

Improving or eliminating unhealthy environments may go a long way in improving healthy food consumption. Even if consumers decide to go elsewhere to get unhealthy food, living in a healthy food environment can communicate directly and indirectly to consumers that healthy food is typical, ubiquitous, desirable, and habitual, which may affect the entirety of communicative contexts, attitudes, and, ultimately, behavior. In other words, consumers normalize healthy foods and de-normalize unhealthy ones.

By using the CMM as a theoretical model that can be applied to health communication, we provide evidence of its uses beyond civic and political participation. With few exceptions (e.g., Abril 2016; Kwon et al. 2013), the CMM has not been tested outside of these contexts. Moreover, similar to the role of political campaigns acting as an external force to the CMM (Shah et al. 2007), the perceived food environment infuses the CMM with direct effects on reflective food consumption and indirect effects rippling through the 
model. Overall, our model supports an O-S-R-O-R (Orientations-Stimulus-ReasoningOrientations-Response) representation of effects, similar to Jung and colleagues (Jung et al. 2011), with the perceived food environment affecting each step (news, talk, and attitudes) beyond initial orientations. Future research should help determine which causal pathways are more important in terms of their effects on healthy food consumption since our model with cross-sectional data is not appropriate to undertake such evaluation of causality.

\subsection{Limitations}

Despite these promising results, we must note some limitations. First, due to the nature of the cross-sectional data, we are unable to make any causal inferences. It is thereore likely that the direction of the relationships posed in our model (Figure 4) could be reversed. However, (a) our model mimics the well-researched CMM literature, which has tested the direction of these effects - as we have proposed them-with longitudinal data, therefore asserting the causality pathways (Shah et al. 2007); (b) no significant modification indices indicated that the hypothesized direction of effects should be otherwise; and (c) models in which some of the relationships were reversed did not have a satisfactory model fit and had higher AIC and BIC criteria. Additionally, the food environment can be thought of as an antecedent since it is unlikely that any of the variables in the model could influence the food environment.

Furthermore, some of our measures were single items, which may pose measurement issues in path analysis (Kaplan 2009), so future research should include a more reliable operationalization of our constructs. This includes the operationalization of food environments, especially as it only considers organic foods. Organic foods are not the only determinant of healthy food environments but can be considered a proxy (Inglis et al. 2008). Finally, our dependent variable is limited to reflective consumption (consumption of organics, non-GMOs, local items, and consumption that uses the label for decision-making). Healthy foods span beyond reflective consumption, so we may be underestimating the effect of perceived food environments and the CMM in our analysis. The next batch of studies could benefit from using outcomes that more closely represent the consumption of healthy foods in lacking food environments.

Even with these shortcomings, the results uncovered are revealing. Our food environments both directly and indirectly (through communicative contexts) influence our attitudes toward consumption and daily eating habits. When considering the negative health outcomes plaguing the United States-including heart disease, stroke, and diabetesit seems reasonable to promote food environments that provide access to healthy foods (fresh vegetables and whole grains) as a means of mitigating premature mortality rates. Over time, and with the cultivation of a healthy food environment, it may be possible to reverse the effects of ingrained negative attitudes, marginal discourse about healthy foods and diet (e.g., cooking), and nominal use of media focused on the effects of a healthy diet (e.g., health news). By disseminating positive health-centric messaging in networks and having an accessible food environment, attitudes and behaviors may be influenced for the better. These developments cannot happen overnight, however.

\subsection{Conclusions}

This study sought to introduce the importance of communicative contexts in partially explaining the negative relationship between lacking food environments and reflective food consumption. In the past, these two models (food environments and healthy food consumption; the CMM model of media use and health outcomes) were studied separately. Our results highlight the possibility that the communicative contexts of food environments may shape health outcomes thus helping explain the missing piece of the food environment puzzle, and the representative sample allows us to generalize beyond middle-class white adult behavior. Still, adequate healthy food intake may require much more than our model can explain. For instance, issues of poverty and race can make it harder to simply change food consumption as a result of better food environments. Public policy and cultural 
change are necessary if tangible progress on this issue is to happen, something that current research underscores (see Niederdeppe et al. 2016).

By illuminating the indirect effects of food environments, we are better able to understand how they factor in communicating what is habitual and acceptable in terms of healthy food consumption. This means we must consider the food environment as a communicative context alongside the mass media, interpersonal networks, social media, and technology. Likewise, our findings also provide evidence that the relationship between the food environment and behavioral outcomes related to food may have been underestimated. That is, the relationship between the food environment and food-related outcomes may go beyond direct effects. In all, the main contribution showcases the relationships between the perceived food environment and communication variables.

Despite imperfect measures of our constructs, we found that the food environment helps explain our health news media use and posterior discussion, thus providing more evidence for the food environment puzzle. Simply put, this study demonstrates one more reason why food environments matter.

Supplementary Materials: The following are available online at https:/ /www.mdpi.com/article/10 .3390/journalmedia2030030/s1.

Author Contributions: Conceptualization, E.P.A.; methodology, E.P.A.; software, E.P.A.; validation, E.P.A.; formal analysis, E.P.A.; investigation, E.P.A. and C.O.; writing-original draft preparation, E.P.A. and C.O.; writing-review and editing, E.P.A. and C.O.; visualization, E.P.A.; supervision, E.P.A. All authors have read and agreed to the published version of the manuscript.

Funding: Authors received no funding for this research.

Institutional Review Board Statement: Pew Research Center underwent a Review Process prior to fielding.

Informed Consent Statement: Participants all signed an informed consent prior to participate.

Data Availability Statement: Data can be accessed here: https:/ / www.pewresearch.org/internet/ dataset/american-trends-panel-wave-17/ (Accessed on 1 February 2021).

Acknowledgments: The authors wish to thank Pew Internet Research for letting us use the data in this study.

Conflicts of Interest: The authors declare no conflict of interest.

\section{Notes}

1 RR1 (Response Rate) codes were modified to reflect the fact that this survey was a panel survey, not an RDD survey. All sample members were eligible.

2 When using a proxy, attention must be paid to both under- and overestimation of the true value of healthy food consumption. In terms of underestimation, it is entirely possible to consume healthy foods without purchasing organic, GMO-free, or local foodstuffs, and even without looking at labels. Therefore, some healthy food consumption is not accounted for in our dependent variable, which makes its use in our model, if anything, a conservative measure of healthy food consumption (i.e., our measure is a subset of the true healthy foods consumption). To be clear, we make no claims that organic, non-GMO, or even local foods are healthier, but that the (conscious) consumption of these types of food is associated with a healthy lifestyle (Kesse-Guyot et al. 2013) and is healthy. In terms of overestimation, we could not find studies, to our knowledge, linking unhealthy food habits and the consumption of organic, local, or non-GMO foods, or using food labels as consumption-decision tools-not even when such associations were sought (Baudry et al. 2017). While it is genuinely possible to eat organic, non-GMO, local, or purchase based on label-reading decisions and unhealthy foods, this is not only atypical but also fairly marginal. In conclusion, we consider the variable reflective food consumption to be a conservative measure of true healthy food consumption having little risk of being confounded with unhealthy food consumption.

3 All betas are reported as STDX standardized betas, which use the variances of the continuous latent variables and the background and/or outcome variables (see www.statmodel.com). (Accessed on 1 February 2021). 


\section{References}

Abril, Eulàlia P. 2016. Explaining voluntary blood donation from a communication perspective. Cuadernos 38: 17-33. [CrossRef]

Abril, Eulàlia P., and Hernando Rojas. 2018. Silencing Political Opinions: An Assessment of the Influence of Geopolitical Contexts in Colombia. Communication Research 45: 55-82. [CrossRef]

Abt SRBI. 2016. Pew Research Center's American Trends Panel-Wave 17. Methodology Report. New York: Abt SRBI.

Ajzen, Icek, and Martin Fishbein. 1977. Attitude-behavior relations: A Theoretical analysis and review of empirical research. Psychological Bulletin 84: 888-918. Available online: http://www.thecre.com/tpsac/wp-content/uploads/2011/02/Appendix2 _AttitudevsAction_ByAjzenFishbein1977.pdf (accessed on 1 February 2021). [CrossRef]

Alber, Julia M., Sarah H. Green, and Karen Glanz. 2018. Perceived and observed food environments, eating behaviors, and BMI. American Journal of Preventive Medicine 54: 423-29. [CrossRef]

Albert, Stephanie Lynn. 2017. \#Consumingitall: Understanding the Complex Relationship between Media Consumption and Eating Behaviors. Los Angeles: University of California Los Angeles, Available online: https://escholarship.org/uc/item/1f75j34r (accessed on 1 February 2021).

Arena, Ross, Amy McNeil, Michael Sagner, and Carl J. Lavie. 2017. Healthy Living: The Universal and Timeless Medicine for Healthspan. Progress in Cardiovascular Diseases 59: 41-21. [CrossRef] [PubMed]

Baudry, Julia, Sandrine Péneau, Benjamin Allès, Mathilde Touvier, Serge Hercberg, Pilar Galan, Marie-Josèphe Amiot, Denis Lairon, Caroline Méjean, and Emmanuelle Kesse-Guyot. 2017. Food choice motives when purchasing in organic and conventional consumer clusters: Focus on sustainable concerns (the nutrinet-santé cohort study). Nutrients 9: 88. [CrossRef] [PubMed]

Black, Christina, Graham Moon, and Janis Baird. 2014. Dietary inequalities: What is the evidence for the effect of the neighbourhood food environment? In Health and Place. Amsterdam: Elsevier Ltd., vol. 27, pp. 229-42. [CrossRef]

Caldwell, Erin M., M. Miller Kobayashi, Wendy Dubow, and Sonya Wytinck. 2009. Perceived access to fruits and vegetables associated with increased consumption. Public Health Nutrition 12: 1743-50. [CrossRef]

Caspi, Caitlin E., Glorian Sorensen, S. V. Subramanian, and Ichiro Kawachi. 2012. The local food environment and diet: A systematic review. Health and Place 18: 1172-87. [CrossRef]

Chen, Danhong, Edward C. Jaenicke, and Richard J. Volpe. 2016. Food environments and obesity: Household diet expenditure versus food deserts. American Journal of Public Health 106: 881-88. [CrossRef]

Cho, Jaeho, Dhavan V. Shah, Jack M. McLeod, Douglas M. McLeod, RosanneM. Scholl, and Melissa R. Gotlieb. 2009. Campaigns, reflection, and deliberation: Advancing an O-S-R-O-R model of communication effects. Communication Theory 19: 66-88. [CrossRef]

Cooksey-Stowers, Kristen, Marlene B. Schwartz, and Kelly D. Brownell. 2017. Food swamps predict obesity rates better than food deserts in the United States. International Journal of Environmental Research and Public Health 14: 1366. [CrossRef]

Courtemanche, Charles, and Art Carden. 2011. Supersizing supercenters? The impact of Walmart Supercenters on body mass index and obesity. Journal of Urban Economics 69: 165-81. [CrossRef]

Cummins, Steven. 2007. Commentary: Investigating neighbourhood effects on health—Avoiding the "Local Trap". International Journal of Epidemiology 36: 355-57. [CrossRef] [PubMed]

Dubowitz, Tamara, Madhumita Ghosh-Dastidar, Christine Eibner, Mary E. Slaughter, Meenakshi Fernandes, Eric A. Whitsel, Chloe E. Bird, Adria Jewell, Karen L. Margolis, Wenjun Li, and et al. 2012. The women's health initiative: The food environment, neighborhood socioeconomic status, BMI, and blood pressure. Obesity 20: 862-87. [CrossRef]

Dubowitz, Tamara, Madhumita Ghosh-Dastidar, Deborah A. Cohen, Robin Beckman, Elizabeth D. Steiner, Gerald P. Hunter, Karen R. Flórez, Christina Huang, Christine A. Vaughan, Jennifer C. Sloan, and et al. 2015. Diet and perceptions change with supermarket introduction in a dood desert, but not because of supermarket use. Health Affairs 34: 1858-68. [CrossRef] [PubMed]

Eagly, Alice Hendrickson, and Shelly Chaiken. 1993. The Psychology of Attitudes. Fort Worth: Harcourt Brace Jovanovich College Publishers.

Fishbein, Martin, and Icek Ajzen. 1975. Belief, Attitude, Intention and Behavior: An Introduction to Theory and Research. Boston: Addison-Wesley.

Flint, Ellen, Steven Cummins, and Stephen Matthews. 2013. Do perceptions of the neighbourhood food environment predict fruit and vegetable intake in low-income neighbourhoods? Health and Place 24: 11-15. [CrossRef]

Friedland, Lewis A., and Jack M. McLeod. 1999. Community integration and mass media: A reconsideration. In Mass Media, Social Control, and Social Change: A Macrosocial Perspective. Edited by David Demers and Kasisomayajula Viswanath. Ames: Iowa State University Press, pp. 197-226.

Gase, Lauren N., Beth Glenn, and Tony Kuo. 2016. Self-efficacy as a mediator of the relationship between the perceived food environment and healthy eating in a low income population in Los Angeles County. Journal of Immigrant and Minority Health 18: 345-52. [CrossRef]

Geller, Alan C., Karen Emmons, Daniel R. Brooks, Zi Zhang, Catherine Powers, Howard K. Koh, Arthur J. Sober, Donald R. Miller, Frederick Li, Frank Haluska, and et al. 2003. Skin cancer prevention and detection practices among siblings of patients with melanoma. Journal of the American Academy of Dermatology 49: 631-38. Available online: https: / /ac-els-cdn-com.proxy.cc.uic.edu/S0190962203021261/1-s2.0-S0190962203021261-main.pdf?_tid=98c8eee1-a32b44a0-9ecd-929b6f406857andacdnat=1520616800_3121296f099d3f9f4fda8806c6b3f503 (accessed on 1 February 2021). [CrossRef] 
Gil de Zúñiga, Homero, Brian Weeks, and Alberto Ardèvol-Abreu. 2017. Effects of the news-finds-me perception in communication: Social media use implications for news seeking and learning about politics. Journal of Computer-Mediated Communication 22: 105-23. [CrossRef]

Glanz, Karen, James F. Sallis, Brian E. Saelens, and Lawrence D. Frank. 2005. Healthy nutrition environments: Concepts and measures. American Journal of Health Promotion. 19, pp. 330-33. Available online: https:/ / pdfs.semanticscholar.org/e34b /bd76486cc91773d0 74ab0c0b4763eb520f53.pdf (accessed on 1 February 2021).

Inglis, Victoria, Kylie Ball, and David Crawford. 2008. Evidence-based public health policy and practice Socioeconomic variations in women's diets: What is the role of perceptions of the local food environment? Journal of Epidemiology and Community Health 62: 191-97. Available online: http:/ / www.jstor.org/stable/20789214 (accessed on 1 February 2021). [CrossRef]

Jardim, Thiago Veiga, Dariush Mozaffarian, Shafika Abrahams-Gessel, Stephen Sy, Yujin Lee, Junxiu Liu, Yue Huang, Colin Rehm, Parke Wilde, Renata Micha, and et al. 2019. Cardiometabolic disease costs associated with suboptimal diet in the United States: A cost analysis based on a microsimulation model. PLoS Medicine 16: e1002981. [CrossRef]

Jung, Nakwon, Yonghwan Kim, and Homero. Gil de Zúñiga. 2011. The mediating role of knowledge and efficacy in the effects of communication on political participation. Mass Communication and Society 14: 407-30. [CrossRef]

Kaplan, David. 2009. Structural Equation Modeling: Foundations and Extensions. Los Angeles: AGE Publications, vol. 10.

Kaase, Max, and Andrew Kohut. 1996. Estranged Friends?: The Transatlantic Consequences of Societal Change. New York: Council on Foreign Relations Press.

Kemmer, Debbie, Annie S. Anderson, and David W. Marshall. 1998. Living together and eating together: Changes in food choice and eating habits during the transition from single to married/cohabiting. The Sociological Review 46: 48-72. [CrossRef]

Kesse-Guyot, Emmanuelle, Sandrine Péneau, Christine Méjean, Fabien Szabo de Edelenyi, Pilar Galan, Serge Hercberg, Denis Lairon, and Thierry Alquier. 2013. Profiles of organic food consumers in a large sample of French adults: Results from the Nutrinet-Santé cohort study. PLoS ONE 8: e76998. [CrossRef] [PubMed]

Kilanowski, Jill F. 2010. Migrant farmworker mothers talk about the meaning of food. The American Journal of Maternal/Child Nursing 35: 330-35. [CrossRef] [PubMed]

Kornfield, Rachel Glen Szczypka, Lisa M. Powell, and Sherry L. Emery. 2015. Televised obesity-prevention advertising across US media markets: Exposure and content, 2010-2011. Public Health Nutrition 18: 983-93. [CrossRef] [PubMed]

Kwon, Min-Woo, Woohyun Yoo, and Michael Aguilar. 2013. Taking the die out of diet: Media and interpersonal communication's impact on healthy eating habits. Journal of Communication in Healthcare 6: 3-12. [CrossRef]

Larson, Nicole I., Mary T. Story, and Melissa C. Nelson. 2009. Neighborhood Environments. Disparities in Access to Healthy Foods in the U.S. American Journal of Preventive Medicine 36: 74-81. [CrossRef] [PubMed]

Lucan, Sean C., and Nandita Mitra. 2012. The food environment and dietary intake: Demonstrating a method for GIS-mapping and policy-relevant research. Journal of Public Health 20: 375-85. [CrossRef]

Lucan, Sean C., Amy Hillier, Clyde B. Schechter, and Karen Glanz. 2014. Objective and self-reported factors associated with foodenvironment perceptions and fruit-and-vegetable consumption: A multilevel analysis. Preventing Chronic Disease 11: 130324. [CrossRef]

Mai, Robert, and Stefan Hoffmann. 2015. How to combat the unhealthy = Tasty intuition: The influencing role of health consciousness. Journal of Public Policy and Marketing 34: 63-83. [CrossRef]

Markus, Hazel, and Robert B. Zajonc. 1985. The cognitive perspective in social psychology. In The Handbook of Social Psychology. Edited by Gardner Lindzey and Elliot Aronson. New York: Random House, vol. 1, pp. 137-230.

McKinley, Christopher J. 2008. Media and interpersonal predictors of healthy eating behavior. Paper presented at the Conference Papers-International Communication Association, Montreal, Canada, May 1-30.

McLeod, Jack M., Katie Daily, Zhongshi Guo, William P. Eveland Jr, Jan Bayer, Seungchan Yang, and Hsu Wang. 1996. Community integration, local media use, and democratic processes. Communication Research 23: 463-87. [CrossRef]

Micha, Renata, Jose L. Peñalvo, Frederick Cudhea, Fumiaki Imamura, Colin D. Rehm, and Dariush Mozaffarian. 2017. Association between dietary factors and mortality from heart disease, stroke, and type 2 diabetes in the United States. JAMA-Journal of the American Medical Association 317: 912. [CrossRef] [PubMed]

Moore, Latetia V., Ana V. Diez Roux, and Shannon Brines. 2008. Comparing perception-based and geographic information system (GIS)-based characterizations of the local food environment. Journal of Urban Health 85: 206-16. [CrossRef]

Morland, Kimberly B., and Kelly R. Evenson. 2009. Obesity prevalence and the local food environment. Health and Place 15: 491-95. [CrossRef]

Nagler, Rebekah H., and Robert C. Hornik. 2012. Measuring media exposure to contradictory health Information: A comparative analysis of four potential measures. Communication Methods and Measures 6: 56-75. [CrossRef] [PubMed]

National Institutes of Health, National Heart, Lung, and Blood Institute. 2017. Overweight and Obesity. Available online: https: //www.nhlbi.nih.gov/health/health-topics/topics/obe/ (accessed on 1 February 2021).

Nguyen, Quynh C., Hsien-Wen Meng, Dapeng Li, S. Kath, M. McCullough, D. Paul, P. Kanokvimankul T. X. Nguyen, and F. Li. 2017. Social media indicators of the food environment and state health outcomes. Public Health 148: 120-128. [CrossRef]

Niederdeppe, Jeff, Sungjong Roh, and Caitlin Dreisbach. 2016. How narrative focus and a statistical map shape health policy support among state legislators. Health Communication 31: 242-55. [CrossRef] [PubMed] 
Noelle-Neumann, Elisabeth. 1974. The spiral of silence: A theory of public opinion. Journal of Communication 24: 43-51. [CrossRef]

Ogden, Cynthia L., Margaret D. Carroll, Cheryl D. Fryar, and Katherine M. Flegal. 2015. Prevalence of Obesity among Adults and Youth: United States, 2011-2014. Available online: https://www.cdc.gov/nchs/data/databriefs/db219.pdf (accessed on 1 February 2021).

Pitt, Erin, Danielle Gallegos, Tracy Comans, Cate Cameron, and Lukar Thornton. 2017. Exploring the influence of local food environments on food behaviours: A systematic review of qualitative literature. Public Health Nutrition 20: 2393-405. [CrossRef] [PubMed]

Powell, Lisa M., Sandy Slater, Donka Mirtcheva, Yanjun Bao, and Frank J. Chaloupka. 2007. Food store availa-bility and neighborhood characteristics in the United States. Preventive Medicine 44: 189-95. [CrossRef] [PubMed]

Ramírez, A. Susana, Derek Freres, Lourdes S. Martinez, Nehama Lewis, Angel Bourgoin, Bridget J. Kelly, Chul-Joo Lee, Rebekah Nagler, J. Sanford Schwartz, and Robert C. Hornik. 2013. Information seeking from media and family/friends increases the likelihood of engaging in healthy lifestyle behaviors. Journal of Health Communication 18: 527-42. [CrossRef] [PubMed]

Rimal, Rajiv N., June A. Flora, and Caroline Schooler. 1999. Achieving Improvements in Overall Health Orientation. Communication Research 26: 322-48. [CrossRef]

Roskos-Ewoldsen, David R., Jessy H. Yu, and Nancy Rhodes. 2004. Fear appeal messages affect accessibility of attitudes toward the threat and adaptive behaviors. Communication Monographs 71: 49-69. [CrossRef]

Shah, Dhavan V., Jaeho Cho, William P. J. Eveland, and Nojin Kwak. 2005. Information and Expression in a Digital Age. Modeling Internet Effects on Civic Participation. Communication Research 32: 531-65. [CrossRef]

Shah, Dhavan. V., Jaeho Cho, Seungahn Nah, Melissa R. Gotlieb, Hyunseo Hwang, Nam-Jin Lee, Rosanne M. Scholl, and David M. McLeod. 2007. Campaign Ads, Online Messaging, and Participation: Extending the Communication Mediation Model. Journal of Communication 57: 676-703. [CrossRef]

Sun, Yu-Hua Christine. 2008. Health concern, food choice motives, and attitudes toward healthy eating: The mediating role of food choice motives. Appetite 51: 42-49. [CrossRef]

Sundin, Ebba, Linus Andersson, Malin Hallén, and Martin Danielsson. 2016. Local Images of Health and Lifestyle: Free Newspapers, Community-construction and the "Healthy City". Paper presented at the ECREA Pre-Conference: Dealing with the Local: Proximity and Community, Prague, Czech Republic, November 8.

Thompson, Claire, Steven Cummins, Tim Brown, and Rosemary Kyle. 2013. Understanding interactions with the food environment: An exploration of supermarket food shopping routines in deprived neighbourhoods. Health and Place 19: 116-23. [CrossRef] [PubMed]

Torjusen, Hanne, Geir Lieblein, Margareta Wandel, and Charles. A. Francis. 2001. Food system orientation and quality perception among consumers and producers of organic food in Hedmark County, Norway. Food Quality and Preference 12: 207-16. [CrossRef]

U.S. Department of Health and Human Services, Centers for Disease Control and Prevention, and National Center for Health Statistics. 2016. Health United States Report 2016. Available online: https://www.cdc.gov/nchs/data/hus/hus16.pdf\#019 (accessed on 1 February 2021).

Ver Ploeg, Michele, Vince Breneman, Paula Dutko, Ryan Williams, Samantha Snyder, Chris Dicken, and Phillip Kaufman. 2012. What Is the Issue? Access to Affordable and Nutritious Food: Updated Estimates of Distance to Supermarkets Using 2010 Data. Available online: https: / / www.ers.usda.gov/webdocs / publications/45032/33844_err143_summary.pdf?v=41505 (accessed on 1 February 2021).

Walker, Renee E., Christopher R. Keane, and Jessica G. Burke. 2010. Disparities and access to healthy food in the United States: A review of food deserts literature. Health and Place 16: 876-84. [CrossRef]

Wang, Youfa, Peng Jia, Xi Cheng, and Hong Xue. 2019. Improvement in food environments may help prevent childhood obesity: Evidence from a 9-year cohort study. Pediatric Obesity 14: e12536. [CrossRef] [PubMed] 